\title{
Nanorg microbial factories: Light-driven renewable biochemical synthesis using quantum dot-bacteria nano-biohybrids
}

\author{
Yuchen Ding, ${ }^{1,2,3, \#}$ John R. Bertram, 3 ,4, \# Carrie Eckert, ${ }^{3,5}$ Rajesh Reddy Bommareddy, ${ }^{6}$ Rajan \\ Patel, ${ }^{6}$ Alex Conradie, ${ }^{7}$ Samantha Bryan, ${ }^{7}$ Prashant Nagpal $1,3,4 *$ \\ ${ }^{1}$ Chemical and Biological Engineering, University of Colorado Boulder \\ ${ }^{2}$ Chemistry and Biochemistry, University of Colorado Boulder \\ ${ }^{3}$ Renewable and Sustainable Energy Institute (RASEI), University of Colorado Boulder \\ ${ }^{4}$ Materials Science and Engineering, University of Colorado Boulder, Boulder, CO 80303 \\ ${ }^{5}$ National Renewable Energy Laboratory (NREL), Golden, CO \\ ${ }^{6}$ SBRC, Centre for Biomolecular Sciences, University of Nottingham, Nottingham, NG7 2RD, \\ United Kingdom. \\ ${ }^{7}$ Department of Chemical and Environmental Engineering, University of Nottingham, NG7 2RD, \\ United Kingdom \\ \#These authors contributed equally to the manuscript
}

\begin{abstract}
:
Living cells do not interface naturally with nanoscale materials, although such artificial organisms can have unprecedented multifunctional properties, like wireless activation of enzyme function using electromagnetic stimuli. Realizing such interfacing in a nano-biohybrid organism (or nanorg) requires (1) chemical coupling via affinity binding and self-assembly, (2) the energetic coupling between optoelectronic states of artificial materials with the cellular process, and (3) the design of appropriate interfaces ensuring biocompatibility. Here we show that seven different coreshell quantum dots (QDs), with excitations ranging from ultraviolet to near-infrared energies, couple with targeted enzyme sites in bacteria. When illuminated by light, these QDs drive the renewable production of different biofuels and chemicals using carbon-dioxide $\left(\mathrm{CO}_{2}\right)$, water, and nitrogen (from air) as substrates. These QDs use their zinc-rich shell facets for affinity attachment to the proteins. Cysteine zwitterion ligands enable uptake through the cell, facilitating cell survival. Together, these nanorgs catalyze light-induced air-water- $\mathrm{CO}_{2}$ reduction with a high turnover


number (TON) of $\sim 10^{6}-10^{8}$ (mols of product per mol of cells) to biofuels like isopropanol (IPA), 2,3-butanediol (BDO), $\mathrm{C}_{11}-\mathrm{C}_{15}$ methyl ketones (MKs), and hydrogen $\left(\mathrm{H}_{2}\right)$; and chemicals such as formic acid (FA), ammonia $\left(\mathrm{NH}_{3}\right)$, ethylene $\left(\mathrm{C}_{2} \mathrm{H}_{4}\right)$, and degradable bioplastics polyhydroxybutyrate (PHB). Therefore, these resting cells function as nano-microbial factories powered by light.

\section{INTRODUCTION:}

Wireless control over specific cellular function has been a long-standing objective in life sciences. ${ }^{1}$ While such external regulation can provide unprecedented insights into molecular biology, it can also form the basis for several new biotechnological techniques ranging from diagnosis and therapeutics to the generation of biofuels and bioproducts. Here we show a platform technology for the bottom-up design of nano-biohybrid organisms (or nanorgs) using semiconductor nanoparticles which can be tailored for affinity binding to desired proteins by facile transport, uptake, and self-assembly, and matched to the electrochemical potential of the enzyme to trigger them externally using electromagnetic radiation, like light. As a specific application and to demonstrate broader applicability of our method, we demonstrate the formation of such living nanorgs using different strains of Azotobacter vinelandii and Cupriavidus necator bacteria and show desired enzyme activation for targeted chemical generation using light in these nonphotosynthetic microbes. These naturally occurring and synthetic bacteria can accomplish industrially important reactions using chemical energy to generate electrons and reduce renewable chemical feedstocks like $\mathrm{CO}_{2}, \mathrm{H}_{2} \mathrm{O}$, and air, and can be labeled as living factories (Fig.1a). ${ }^{2}$ Both $A$. vinelandii and $C$. necator normally derive the energy needed for the chemical transformations of feedstocks to biofuels from sugars, since such non-photosynthetic microbes cannot directly utilize the sunlight like the photoautotrophs. Attempts have been made to combine the desired functionality of direct light-activation in cell-free extracts or purified enzymes for in vitro biocatalysis or bioelectrocatalysis. ${ }^{3-6}$ But these strategies have some limitations due to enzyme deactivation in the air or during chemical conversion, without an ability to regenerate the enzyme using the living cell. Other in vivo efforts have been targeted in specific strains of whole nonphotosynthetic bacteria, ${ }^{7,8}$ but can limit their applicability due to specific tolerance of the bacteria to inorganic elements and a smaller range of chemicals that can be made. Further, both these processes lack the desired specificity of enzyme activation in living cells, and there is a need to 
develop a platform technology for such desired living nano-biohybrids for applications beyond solar energy conversion and catalysis, to new avenues in diagnosis and therapeutics. There has been an intensive search for a new method to combine multiple functionalities (e.g., light, voltage, or magnetic field stimulation) of inorganic nanomaterials with the versatility of metabolic networks in living cells, to simply "grow" such hybrid catalysts or convert existing living cells into nanorgs, by the simple addition of inorganic nanomaterials to the cellular medium/water.

We demonstrate the potential of our multifunctional living nanorgs by suspending a range of different normally non-photosynthetic bacteria in buffered water (in the absence of any sugar) and converting renewable feedstocks like air and $\mathrm{CO}_{2}$ directly into biofuels and specialty chemicals using these solar-powered factories (Fig.1a). Using different core semiconductor nanocrystals or quantum dots (QDs) with tunable bandgap energies (such as cadmium sulfide (CdS), cadmium selenide $(\mathrm{CdSe})$, indium phosphide $(\mathrm{InP})$, and copper zinc tin sulfide $\left(\mathrm{Cu}_{2} \mathrm{ZnSnS}_{4}\right)$ ), and an optimized two monolayer zinc sulfide $(\mathrm{ZnS})$ shell, we utilize the chemical binding affinity of zinc with either a histidine-tagged MoFe nitrogenase in A. vinelandii or Fe-S clusters in hydrogenases and quinones in C. necator, demonstrating the facile formation of nanorgs by self-assembly and simple addition of QDs in the media/buffered water. These biocatalysts demonstrate high conversion yields to target products (10-100 $\mathrm{mg}$ of product/g of dry weight of cells/day) without the utilization of sugar as a source of energy, comparable to or even exceeding $(>150 \%)$ native production levels. The high quantum yields from such light-driven chemical generation (13\%) depend on the optimization between biocatalyst turnover, incident light-flux, and the amount of light absorbed. While the enzyme turnover and mismatch with the photon flux limits the overall light-to-chemical conversion efficiency (16-20\%), better matching the light absorbed in these biohybrids with enzymatic conversion rates through enzyme upregulation or matching incident photon flux can result in improved photon-to-fuel conversion. Together, these results demonstrate an unprecedented opportunity for development of these nanorgs as renewable sugar-free microbial factories for the production of biofuels and chemicals using sunlight in a scalable process, but also as a means of externally regulating the cellular function of living cells using electromagneticstimuli such as light, sound, or magnetic field.

\section{RESULTS AND DISCUSSION}




\section{Choice of $Q D$ core with desirable redox potential}

The first step towards the development of such living organisms is in vivo site-specific selfassembly, for chemically and energetically coupling the QDs and specific proteins within the synthetic bacteria. While chemical conversion in biohybrid systems can also be achieved using the formation of intermediates using inorganic catalysis or electrochemistry, followed by utilization of these intermediates by bacteria, ${ }^{9-12}$ direct chemical conversion of inexpensive substrates using light in a bacteria as a platform is still challenging. Such a platform method, envisioned as nongenetically encoded (enzyme regeneration would lead to loss of photosensitization), selfassembled nano-biohybrid enzymes in nanorgs, could even allow selectively triggering cell function for diagnostic evaluation or therapy. To accomplish the desired reaction driven by QD excitation, the reaction center and attachment site for the QD were identified. We designed these nanorgs by appropriately choosing the QD size and material ${ }^{13,14}$ (core-shells, since different materials were required for energetic alignment and chemical coupling/biocompatibility), QD surface charge and ligands, ${ }^{15,16}$ and the desired site-specific attachment. ${ }^{17}$ The core QDs were selected using their size- and material-tunable conduction/valence bandedge positions (Fig.1b) and absorption spectrum, covering the whole ultraviolet-visible-near infrared (UV-VIS-NIR) spectra (Fig.1a,c). To ensure proper energetic alignment and efficient electron injection from the conduction band of photoexcited QDs to selected enzymes (e.g., the molybdenum-iron nitrogenase (MFN) enzyme $3,18,19$ in $A$. vinelandii, $[\mathrm{Fe}-\mathrm{S}]$ clusters in the hydrogenases and quinones of $C$. necator), we conducted in vitro experiments with the purified enzyme-QD biohybrids for lightinduced catalysis. Our choice of QDs was driven by their strong light absorption in the specific wavelength range (Fig.1a), easy control of their size,${ }^{20}$ and tunability of their quantum-confined conduction/valence band positions. ${ }^{21}$ We investigated different sizes of CdS QDs (Fig.S1a) to absorb the ultraviolet, CdSe QDs (Fig.S1b) to absorb the visible, and InP and CZTS QDs to absorb the near-infrared (NIR) photons. These QDs were specifically chosen to energetically match the reduction potential of the enzymes, ${ }^{22,23}$ using detailed electrochemical measurements of the QDs ${ }^{24-}$ 26 (Fig.1b, S2, Table S3). While the QDs had the desired electrochemical potential, simply mixing the QDs with the cell lysate led to low or insignificant photocatalytic activity in QD-enzyme biohybrids. Therefore, we developed a robust and tunable platform to evaluate affinity attachment to the desired enzymes, to ensure efficient charge injection and good biocompatibility. 


\section{Affinity binding and self-assembly}

Ensuring affinity attachment for chemical coupling and self-assembly between the QDs and the targeted enzymes inside the bacteria (Fig.2a), ${ }^{27}$ we screened common biocompatible QD shell materials using large particles for their selectivity in attaching to specific sites on our target proteins. Here, metal-histidine affinity was investigated. We conducted protein-binding tests using the cell lysate (produced from genetically-engineered A. vinelandii DJ995 strain, which contains a His-tagged $\mathrm{MFN}^{18}$ ) with $\mathrm{ZnS}$ and $\mathrm{CdS}$, by incubating them in room temperature followed by eluting the trapped components with imidazole. SDS-PAGE with Coomassie staining for the released protein indicates single band (Fig.2b) with ZnS, showing its selective binding to Histagged MFN. And no such selectivity was seen with CdS. We have also demonstrated such sitespecific binding by using fluorescent CdSe@ZnS core-shell QDs with the cell lysate, by running the mixture through the agarose gel using electrophoresis. Majority of observed fluorescence (Fig.2c) and cadmium (Fig.2d) detected from His-tagged MFN band indicates the specific binding between them. Since simply mixing QDs with the desired electrochemical potential with the cell lysate led to low or insignificant photocatalytic activity in QD-enzyme biohybrids (Fig.2e, MFN), we evaluated potential role for a shell around the QD core. By chnaging the shell thickness around the QDs, we observed that the low photocatalystic activity of the core could be due to poor charge injection efficiency of the photogenerated electron, as shown with strong reduction of subbandgap/trap state recombination (Fig.S1d), clear decrease in interfacial charge injection and capacitance due to trapped charges (Fig.S2e-i) and slower open-circuit potential decay (Fig.S2i, compiled data in Table S4). To maintain the desired energetic coupling of photoelectron production in CdS and the site-selective MFN binding with ZnS, CdS@ZnS core-shell quantum dots were designed to selectively trap the His-tagged MFN from the cell lysate (prepared from the A. vinelandii DJ995 bacteria) and conduct light-induced in vitro redox reactions.

Optimizing the injection of photogenerated electrons from different core QDs to the enzyme active site, the core-shell QDs were synthesized using a layer-by-layer deposition technique, ${ }^{14}$ with precise control of the $\mathrm{ZnS}$ shell thickness (Fig.S1c,d, Table S1). While increased shell thickness ensured site-selective attachment, biocompatibility, improved charge injection of the photogenerated electrons to the active enzyme site, and increased surface passivation reducing surface states/defects; thick $\mathrm{ZnS}$ shells also served as a barrier for charge injection from different 
QDs cores. To realize an optimal design, we coupled CdS@ZnS QDs with nominal x monolayer (ML) ZnS shells (CZS-xML, $x=0 \sim 3$, capped with 3-mercaptopropionic acid (MPA) ligand) with the cell lysate and tested their photocatalytic efficiency in $\mathrm{H}_{2}$ and $\mathrm{NH}_{3}$ production. We used lightinduced $(400 \mathrm{~nm}) \mathrm{H}_{2} \mathrm{O}$ and $\mathrm{N}_{2}-\mathrm{H}_{2} \mathrm{O}$ reduction in $\mathrm{pH}=7.4$ media, utilizing either L-ascorbic acid or HEPES as a sacrificial agent. Here, we observed a significant enhancement of $\mathrm{H}_{2}$ and $\mathrm{NH}_{3}$ generation with the QDs-cell lysate biohybrids, generating a maximum of $615 \mathrm{nmol} / \mathrm{ml}$ cell lysate for $\mathrm{H}_{2}$ production from $\mathrm{H}_{2} \mathrm{O}$ reduction and $527 / 337 \mathrm{nmol} / \mathrm{ml}$ cell lysate $\mathrm{H}_{2} / \mathrm{NH}_{3}$ production from $\mathrm{N}_{2}-\mathrm{H}_{2} \mathrm{O}$ reduction (net production, with correction using the reaction phase containing only QDs, in $30 \mathrm{~min}$ ) using the biohybrids with $2 \mathrm{ML} \mathrm{ZnS-coated} \mathrm{QDs} \mathrm{(Fig.3a,} \mathrm{S6b,c).} \mathrm{As} \mathrm{a} \mathrm{comparison,}$ QDs without MFN attachment (zero ML shell) or with thick shells (three MLs) show a negligible yield. The affinity binding of His-tagged MFN to zinc-rich QDs surface was also confirmed by control experiments (Fig.S6d-f), where the addition of imidazole (coordinates with $\mathrm{Zn}^{2+}$ ) or increasing media acidity (protonates histidine) inhibits such interactions ${ }^{27}$ and hence no $\mathrm{H}_{2}$ or $\mathrm{NH}_{3}$ production was observed (same as the systems with only QDs as control). Optimal design of a 2 ML thick CdS@ZnS QD-MFN biohybrid was also evident by electrochemical impedance spectroscopy (Fig.3b, S2g,h small total capacitance and charge transport resistance), open-circuit potential decay (Fig.S2i, Table S4, reduced non-radiative charge recombination) and photoluminescence (Fig.S1d, removal of surface states). The chemical attachment of QDs (capped with 3-mercaptopropionic acid or cysteine) to the proteins was demonstrated by Fouriertransformed infrared (FTIR) spectra of coupled QDs-CL after washing (to remove any unbound/weakly bound cellular component in CL, Fig.S5g,h), showing characteristic peptide vibration modes and the disappearance of O-H stretching in the QDs-protein complex. Binding of cellular proteins to the QDs was also confirmed by UV-VIS analysis of QDs-CL, purified using centrifugation (Fig.S5a-f). To further investigate the affinity of QDs binding QDs-CL mixtures were separated by gel electrophoresis. Here, highly fluorescent ZnS-capped QDs were detected mainly from the His-tagged MFN band (Fig.2c), where selective QD attachment was confirmed by elemental analysis (Fig.2d) of the His-tagged MFN band and the non-His-tagged protein bands. Using this evidence for affinity attachment, in vitro studies with QDs-cell lysate (to decouple the role of QD transport), we demonstrated the importance of simultaneous optimization of surface tuning, photophysics, and charge tunneling (across QD-shell) in designing highly efficient biohybrids. 


\section{QD biocompatibility and ligands}

Another essential aspect of the QD surface critical for nanorg development was the ligand and the overall charge on QDs, ${ }^{17,28-31}$ which affected their biocompatibility, viability, and the uptake of designed QDs for intracellular self-assembly. Several attempts to combine the desired functionality of QDs with the synthetic versatility of the designed bacteria have relied on cell-free extraction of the enzymes and their coupling with QDs. These approaches showed limitations such as loss of enzyme activity or even deactivation, ${ }^{3-6,18,32}$ low enzyme concentrations, issues with scale-up, and low-activity and TON for chemical conversion. Using QDs capped with similarsized ligands as well as different surface charge (negatively-charged MPA, positively-charged cysteamine (CA), and zwitterion cysteine (CYS)), we tested the viability of bacteria with QDs using three different methods. First, when monitoring cell growth by optical density, we observed that bacteria with CYS-capped QDs exhibited growth similar to no treatment $(<20 \%$ growth inhibition even with $1000 \mathrm{nM}$ QDs), MPA-capped QDs impaired growth moderately (up to 60\%), and CA-capped QDs strongly inhibited growth ( $80 \%)$, especially at high concentrations (Fig.3c, S8a-d). Under light irradiation with non-growing nanorg cells in the photocatalytic media, cell viability was almost unaffected (Fig.S8j-I) with both the CYS-capped QDs and the low concentration MPA-capped QDs. With the higher concentration MPA-capped nanoparticles and even the low $(50 \mathrm{nM})$ concentration of CA-capped QDs, a significant decrease in cell viability was observed. Low cell viability could render the cell unable to remove the oxygen in the air and cause deactivation of the oxygen-sensitive enzymes. ${ }^{3,18,32}$ This leads to low $\mathrm{NH}_{3}$ production in lightinduced air-water reduction using the QDs-living bacterial biohybrids and can be checked by performing the photocatalytic test in a different atmosphere. We observed a significant decrease of $\mathrm{NH}_{3}$ yield in air- $\mathrm{H}_{2} \mathrm{O}$ reduction compared to pure $\mathrm{N}_{2}$ (oxygen-free) $-\mathrm{H}_{2} \mathrm{O}$ (Fig.S11c, d). The second test utilized on the nanorgs to measure the cell viability was the resazurin dye assay, ${ }^{21}$ performed after the photocatalytic test, which also demonstrated high cell viability with both zwitterion and (low concentration) negatively-charged QDs (Fig.3d, S9). A more detailed investigation with colony forming unit analysis (CFU) also showed the same results (Fig.3e), with the highest viability for zwitterion and negatively-charged QDs. Using the cell size of $A$. vinelandii (2.7-6.6 $\times 10^{-15}$ liters), the cell viability, even at high QD concentrations ( $\left.>1000 \mathrm{nM}\right)$, and modest uptake with zwitterion QDs ( $\sim 14 \%$, Fig.3f), we estimated $\sim 10^{4}$ QDs per cell, which guarantees enough QDs in the cell to couple with available MFN enzymes. QD uptake by the cells was also 
visualized using laser-scanning confocal microscopy, showing a uniform distribution of QDs inside the bacteria (Fig.S7). Uniform distribution of QDs throughout the cells (monitored using fluorescent QD in a confocal microscope) proves intracellular QD uptake, enabling self-assembly of QDs with enzymes. While the cellular uptake with positively charged CA-capped QDs was much higher than both negative or zwitterions ligands with similar sizes, the strong non-specific attachment of QDs to negatively-charged cell organelles (like DNA, RNA, proteins) could be responsible for the low cell viability, especially at high CA-capped QD concentrations.

\section{Light-triggered enzyme activation}

Following the design and self-assembly of appropriate QD-bacteria biohybrid nanorgs (QDs with two monolayers thick $\mathrm{ZnS}$ shell, capped with cysteine ligand), we tested their ability to fix the energy of incident light-photons into specific chemical bonds using renewable and inexpensive substrates/feedstocks, like air, water, and $\mathrm{CO}_{2}$. Control experiments with either no QDs, light irradiation, or the cells, show no $\mathrm{NH}_{3}$ or $\mathrm{C}_{2} \mathrm{H}_{4}$ production in $A$. vinelandii and $C$. necator strains (Fig.S10a,b). Using strains with decreased nitrogen fixation capability (A. vinelandii DJ1003, which produces a His-tagged apo-nitrogenase with no MoFe cofactor) and no ethylene pathway (C. necator pBBR1-YFP, with the lack of "efe" gene for ethylene production), significant decrease of ammonia or no ethylene production (Fig.4a) was seen. Similar ammonia production tests were also performed by using CdS QDs (without $\mathrm{ZnS}$ shell) and a $A$. vinelandii strain producing nonHis-tagged MFN (details in the supporting information), where no site-specific zinc-hisditine binding was utilized. In these controls, the ammonia yield also decreased significantly (Fig.4b) to only $\sim 1 / 3$, compared to the zinc-histidine binding. The same tests conducted under lack of available substrate/feedstock (argon atmosphere, so no $\mathrm{N}_{2}$ or $\mathrm{CO}_{2}$ substrate available) also showed no product generation (Fig.4c, S10c). Isotope $\left({ }^{13} \mathrm{C}\right)$ labelling tests (mass spectra, Fig.S10g,h,i) also proves biochemical and biofuel production from ${ }^{13} \mathrm{CO}_{2}$ as the substrate. These ruled out the detection/production of $\mathrm{NH}_{3}$ and other biofuels from either a cellular source (proteins, amino acid, DNA, etc.) or the media. Further controls included lack of product generation without chemical coupling (Fig. 2e), sudden turn-off of light-driven chemical generation by decoupling the QDenzyme (Fig. S6e, f), and lack of significant product formation with synthetic constructs which lack the site for affinity QD attachment or charge injection of photogenerated electrons to drive biocatalysis (Fig.4a). Further experiments also demonstrated the fixing of incident photon energy, 
as chemical fuels provide detailed measurements of light-intensity dependent chemical generation (Fig.S11e), a direct correlation between cell viability of the nanorgs and product yield (Fig.S11bd, see Supporting Information Section 6.2.2 for detailed explanation), and improvement of product formation with nanorg cell optical density leading to higher light absorption (Fig.S11a). The addition of an ionophore (such as 2,4-dinitrophenol (2,4-DNP)) into the photocatalytic system further verified chemical generation via direct transfer of photogenerated electrons from QDs to the enzyme. The continuous chemical generation with a minor decrease in yield (Fig.4d, S10e) indicates a direct electron injection from QDs to enzyme for $\mathrm{NH}_{3} / \mathrm{C}_{2} \mathrm{H}_{4}$ production. Furthermore, the addition of sacrificial donors only had a minor effect on the chemical generation, which strengthens the conclusions from control experiments pointing to the role of QD-enzyme binding (Fig.4e).Intracellular uptake and chemical attachment in nanorgs was also verified using larger nanoparticles, which cannot penetrate the bacterial cell membrane. By using these larger "microparticles" of the same materials, negligible product yields were observed (SI section 6.1.5), providing further evidence for the importance of affinity binding to specific sites as a necessary step for such photon-driven biocatalysis.

After confirming the light-induced redox reaction by direct electron injection in nanorgs, we optimized the conditions further for chemical generation via enzyme activation, utilizing factors including bacterial cell density, irradiation intensity, sacrificial donor concentration (to improve TOF of enzymes), and QD capping ligands and concentration (Fig.S11). We observed a clear correlation between $\mathrm{NH}_{3}$ production and cellular uptake and cell viability in A. vinelandii DJ995 (also confirmed by parallel experiments in air and a pure nitrogen atmosphere, Fig.S11c,d). Using these conditions (detailed in the Supporting Information), we extended our test with various QDs covering absorption spectrum from near-UV, visible, and near-IR. All these QDs form nanorgs with a high TON for $\mathrm{NH}_{3}$ (Fig.5a), up to $10^{7}$ (with CZS, CZSe1, and IPZS QDs). The lower TON for the other nanorgs is mainly due to an unfavorable redox potential match or low absorptivity (especially for CZTS). We also demonstrated the flexibility of the nanorg platform by utilizing direct electron transfer to the living bacteria for different desired fuel generation. By coupling the QDs with a variety of bacterial strains (A. vinelandii DJ995, wild-type and genetically modified C. necator strains, see Supplemental Information, Section 6, for detailed information on strain construction), we were able to create nanorgs for $\mathrm{H}_{2}, \mathrm{NH}_{3}, \mathrm{FA}, \mathrm{C}_{2} \mathrm{H}_{4}, \mathrm{IPA}, \mathrm{BDO}, \mathrm{MKs}$, and PHB production (Fig.5b), with high turnover frequencies up to $10^{7}$ per hour. These nanorgs were able 
to accumulate different amounts of these chemicals (Fig.5c), with up to around $100 \mathrm{mg}$ PHB/g cell dry weight (CDW) in one day. Production of $\mathrm{H}_{2}$ and $\mathrm{NH}_{3}$ with time (Fig.5d, represented as absorbed photon) shows a maximum internal quantum efficiency of about $13.1 \%$. The decrease in quantum efficiency (or the saturation of $\mathrm{NH}_{3} / \mathrm{H}_{2}$ generation) with higher photon numbers was mainly due to the accumulation of the products (functioning as inhibitors), and replenishment of the reaction media (Fig.S12) showed an almost $100 \%$ recovery in $\mathrm{NH}_{3}$ production. As a comparison, with lower absorbed photons, $\mathrm{C}_{2} \mathrm{H}_{4}$ production (Fig.5e, with CZS QDs) kept increasing with no sign of the saturation effects seen in the $\mathrm{NH}_{3}$ production (less inhibition by $\mathrm{C}_{2} \mathrm{H}_{4}$ in the gas phase). However, high photon input (with IPZS QDs) does not help increase the yield, and the quantum yield for $\mathrm{C}_{2} \mathrm{H}_{4}$ production is about one order of magnitude lower than the $\mathrm{NH}_{3}$. This could be due to the un-optimized $\mathrm{C}_{2} \mathrm{H}_{4}$ producing $C$. necator strains (where only a small portion of electrons are converted to $\mathrm{C}_{2} \mathrm{H}_{4}$ due to the complex regulation of native pathways required to produce substrates for the heterologously expressed ethylene-forming enzyme ${ }^{33}$ ), compared to the $\mathrm{N}_{2}$-fixing $A$. vinelandii strains for $\mathrm{NH}_{3}$ production.

\section{Characterization of biocatalytic conversion}

Optimizing the turnover number of light-driven chemical generation using nanorgs, we investigated the turnover frequency of the enzymes by comparing the photon flux for activation of the self-assembled QD-enzyme biohybrids, activated using light for converting photons to chemical bonds. First, we estimated the photon flux per biohybrid enzyme, by determining the light flux $\left(\sim 1.6 \mathrm{~mW} / \mathrm{cm}^{2}\right)$ and using photon energy $(\sim 2 \mathrm{eV})$ to obtain photon flux $\left(5 \times 10^{15}\right.$ photons $/ \mathrm{sec} / \mathrm{cm}^{2}$ ). Using the optical density of the cells and the resulting nanorgs per unit area $\left(\sim 10^{8}\right.$ nanorgs $\left./ \mathrm{cm}^{2}\right)$ and the estimated number of biohybrid enzymes $(\sim 10,000$ biohybrid enzymes/nanorg), we obtained the photon flux per biohybrid enzymes ( $\sim 5000$ photons/biohybrid enzyme/sec). Comparing this to enzyme turnover (for MFN enzyme, $3000 \mathrm{nmol} / \mathrm{mg} / \mathrm{sec}$ for 250 $\mathrm{kDa}$ enzyme $\approx 750 / \mathrm{sec}$ ), we estimated a $\sim 6$-fold incident photons/enzyme turnover, thereby highlighting the mismatch between the number of biohybrid enzymes available for chemical generation in the nanorgs and the high incident flux of light. This would limit the maximum possible quantum efficiency to $\sim 16-20 \%$, further highlighting the high efficiency of enzyme activation using light (13\% in our experiments), and the resulting biofuel and chemical generation using nanorgs. This could be optimized by utilizing synthetic biology tools to upregulate the 
enzymes, thereby coupling the photon flux to enzyme turnover, or reducing the photon flux. To study photon-energy related fuel production, we chose the nanorgs made from IPZS QDs (broader absorption spectrum) with the $\mathrm{C}_{2} \mathrm{H}_{4}$ producing $C$. necator strain, using the same test under different light sources (AM1.5 (with $400 \mathrm{~nm}$ long pass filter), white, purple, blue, and green LED). All these light sources are able to excite the nanorgs for $\mathrm{C}_{2} \mathrm{H}_{4}$ production (Fig.5f), with the purple photons showing the highest efficiency compared to the blue and green photons. More importantly, the high production with AM1.5 irradiation indicates the possibility of using sunlight as an energy source to power the nanorg factories for solar fuel production. To demonstrate the efficiency of our sugar-free nanorg system in different light-excited redox reactions, we compared the chemical production yield in our nanorgs (with wild-type and C. necator strains expressing heterologous genes for the production of $\mathrm{C}_{2} \mathrm{H}_{4}$, IPA, BDO, or MKs) test with the yield in their natural growth (organolithotropic with fructose/glycerol or formate) conditions (Fig.5g). Even for the unoptimized $\mathrm{C}_{2} \mathrm{H}_{4}$, IPA, BDO, and $\mathrm{MK}$ producing strains, we observed a 10-50\% biofuel production, compared to their native conditions. Most notably, when comparing PHB production (a native metabolite produced by $C$. necator), nanorgs exhibit up to $150 \%$ the PHB yield of wild-type cells. Further, the production was easily scaled up from several milliliter tests to liters by simply using a conventional bioreactor with LED panels (Fig.6). Using the wild-type PHB producing strains in the photobioreactor $(\sim 4 \mathrm{~L})$ with a similar condition (as in the $5 \mathrm{ml}$ test scale), we were able to obtain gram-scale production of PHB, with no noticeable change of yield compared to small-scale test. The scaled-up production indicated the potential capability of our system in further scaling up, from lab scale (several liters) to a pilot scale plant $(\sim 1000 \mathrm{~L})$, and eventually even to a commercial level $(>40,000 \mathrm{~L})$ with little change of the configuration. With the replacement of LED lights to sunlight, the solar-powered, green product reactor for renewable generation of these targeted biofuels and bioproducts can also be realized commercially. All these results demonstrate the potential application of our nanorgs platform in direct, scalable, and renewable generation of fuels from sunlight, using air or $\mathrm{CO}_{2}$, and the ability to activate a range of targeted enzymes externally, using electromagnetic stimuli.

Biochemical conversion can also be realized by using electricity. In electro-biochemical synthesis, ${ }^{34}$ the bacteria are immobilized on a modified electrode, which can inject electrons for downstream enzymatic reactions. The two processes: electro-biochemical synthesis and photobiochemical synthesis, can be compared as photovoltaic driven-electrochemical synthesis and 
photocatalysis. The electro-biochemical approach circumvents several requirements of QDsbacteria interactions, including QD uptake and low QD toxicity, making the design easier. However, electro-biochemical synthesis is limited to some special microbes that can exchange electrons with electrodes, and the requirements of immobilization and using redox mediators. Furthermore, there are no mechanisms in specifically targeting a desired enzyme or metabolic pathway for selective biochemical conversions. Therefore, photo-biochemical synthesis by using a designed QD-microbe biohybrid can offer additional advantages over other methods.

\section{CONCLUSION}

In conclusion, we have demonstrated a method for the formation of a living QD-bacterial nanobiohybrid nanorgs via the design of appropriate QDs and facile mixing, self-assembly, and affinity binding to the desired enzymes. Using a range of different light-absorbing QDs and targeted enzymes in different bacterial strains, we demonstrate the broad applicability of the proposed direct activation of the enzyme and the generation of biofuels and chemicals from nonphotosynthetic microbes by simply suspending them in buffered water and bubbling air and/or $\mathrm{CO}_{2}$. Large turnover numbers and frequencies along with the high quantum efficiency for the direct conversion of light into chemicals were obtained for biofuel precursors and specialty chemicals including MKs, BDO, $\mathrm{H}_{2}, \mathrm{IPA}, \mathrm{NH}_{3}, \mathrm{FA}$, and PHB, demonstrating the potential and a possible application of the proposed method. The biochemical conversion yields of the proposed method to simply utilize formed nanorgs, $\mathrm{CO}_{2}$ and water, in absence of sugar, even exceeded the natural yields in growing media $(>150 \%)$, only limited by the enzyme turnover. While maximum achievable quantum efficiency of light-to-chemical conversion can be $16-20 \%$ in the nanorgs, due to slow enzymatic conversion $(\sim 1.3 \mathrm{msec})$ compared to absorbed light flux in the spontaneously self-assembled nano-biohybrids, high conversion efficiencies of light-activated chemical conversion (13\%) highlights the potential of such simple platform for making self-assembled nanorgs and ability of electromagnetic enzyme activation. Further, such catalytic conversion can be optimized by upregulating the desired enzymes using tools in synthetic biology, and better matching the incident photon flux with the achievable turnover of the enzymes, for improved energy conversion. This technique can easily be scaled up; be extended by improved screening for affinity binding to the proteins, expanding the scope of making nanorgs with other prokaryotes and eukaryotes; testing theories in molecular biology; and developing new diagnostic and therapeutic methods using other external stimuli like sound and magnetic field. 


\section{ASSOCIATED CONTENT}

\section{Supporting Information}

Materials and Methods including synthesis and characterization of QDs, Cellular enzyme preparation and characterization, QDs-enzyme complex preparation, interactions between QDs and the living bacteria, formation of QDs-living bacteria nano-biohybrid (nanorgs) for lightinduced air- $\mathrm{CO}_{2}$-water to fuel production, and additional figures as described in the text.

\section{Author Information}

\section{Corresponding Author}

*pnagpal@colorado.edu

\section{Author contributions}

Y.D. and J.R.B. contributed equally to the manuscript.

\section{Notes}

The authors declare no competing financial interests.

\section{Acknowledgments}

The authors would like to acknowledge Prof. Anushree Chatterjee for allowing the use of her laboratory and equipment, Dennis Dean and Valerie Cash (Virginia Tech) for providing the $A$. vinelandii DJ995 and DJ1003 bacteria, Alex Jenkins and Prof. Will Medlin for MS measurements, and Prof. Jeff Cameron for helpful discussions. The imaging work was performed at the BioFrontiers Institute Advanced Light Microscopy Core. Laser scanning confocal microscopy was performed on a Nikon A1R microscope supported by NIST-CU Cooperative Agreement award number 70NANB15H226. The work was funded by the National Science Foundation CAREER award CBET-1351281.

\section{REFERENCES:}

(1) Deisseroth, K. Optogenetics. Nat. Methods 2011, 8 (1), 26-29.

(2) Khalil, A. S.; Collins, J. J. Synthetic Biology: Applications Come of Age. Nature Reviews Genetics. 2010, pp 367-379.

(3) Brown, K. A.; Harris, D. F.; Wilker, M. B.; Rasmussen, A.; Khadka, N.; Hamby, H.; 
Keable, S.; Dukovic, G.; Peters, J. W.; Seefeldt, L. C.; King, P.W. Light-Driven

Dinitrogen Reduction Catalyzed by a CdS:nitrogenase MoFe Protein Biohybrid. Science. 2016, 352 (6284), 448-450.

(4) Milton, R. D.; Abdellaoui, S.; Khadka, N.; Dean, D. R.; Leech, D.; Seefeldt, L. C.;

Minteer, S. D. Nitrogenase Bioelectrocatalysis: Heterogeneous Ammonia and Hydrogen Production by MoFe Protein. Energy Environ. Sci. 2016, 9 (8), 2550-2554.

(5) Milton, R. D.; Cai, R.; Sahin, S.; Abdellaoui, S.; Alkotaini, B.; Leech, D.; Minteer, S. D.

The in Vivo Potential-Regulated Protective Protein of Nitrogenase in Azotobacter Vinelandii Supports Aerobic Bioelectrochemical Dinitrogen Reduction in Vitro. J. Am.

Chem. Soc. 2017, 139 (26), 9044-9052.

(6) Cai, R.; Milton, R. D.; Abdellaoui, S.; Park, T.; Patel, J.; Alkotaini, B.; Minteer, S. D.

Electroenzymatic C-C Bond Formation from CO2. J. Am. Chem. Soc. 2018, 140 (15), 5041-5044.

(7) Sakimoto, K. K.; Wong, A. B.; Yang, P. Self-Photosensitization of Nonphotosynthetic Bacteria for Solar-to-Chemical Production. Science. 2016, 351 (6268), 74-77.

(8) Zhang, H.; Liu, H.; Tian, Z.; Lu, D.; Yu, Y.; Cestellos-Blanco, S.; Sakimoto, K. K.; Yang, P. Bacteria Photosensitized by Intracellular Gold Nanoclusters for Solar Fuel Production. Nature Nanotechnology. 2018, pp 900-905.

(9) Li, H.; Opgenorth, P. H.; Wernick, D. G.; Rogers, S.; Wu, T.-Y.; Higashide, W.; Malati, P.; Huo, Y.-X.; Cho, K. M.; Liao, J. C. Integrated Electromicrobial Conversion of CO2 to Higher Alcohols. Science. 2012, 335 (6076), 1596-1596.

(10) Torella, J. P.; Gagliardi, C. J.; Chen, J. S.; Bediako, K. D.; Colón, B.; Way, J. C.; Silver, P. A.; Nocera, D. G. Efficient Solar-to-Fuels Production from a Hybrid Microbial-waterSplitting Catalyst System. Proc. Natl. Acad. Sci. 2015, 112 (8), 2337-2342.

(11) Liu, C.; Colón, B. C.; Ziesack, M.; Silver, P. A.; Nocera, D. G. Water SplittingBiosynthetic System with CO2 Reduction Efficiencies Exceeding Photosynthesis. Science. 2016, 352 (6290), 1210-1213.

(12) Liu, C.; Gallagher, J. J.; Sakimoto, K. K.; Nichols, E. M.; Chang, C. J.; Chang, M. C. Y.; Yang, P. Nanowire-Bacteria Hybrids for Unassisted Solar Carbon Dioxide Fixation to Value-Added Chemicals. Nano Lett. 2015, 15 (5), 3634-3639.

(13) Alivisatos, A. P. Semiconductor Clusters, Quantum Nanocrystals, and Quantum Dots. 
Science. 1996, 271 (5251), 933-937.

(14) Reiss, P.; Protière, M.; Li, L. Core/shell Semiconductor Nanocrystals. Small. 2009, pp $154-168$.

(15) Medintz, I. L.; Uyeda, H. T.; Goldman, E. R.; Mattoussi, H. Quantum Dot Bioconjugates for Imaging, Labelling and Sensing. Nat. Mater. 2005, 4 (6), 435-446.

(16) Choi, H. S.; Liu, W.; Misra, P.; Tanaka, E.; Zimmer, J. P.; Ipe, B. I.; Bawendi, M. G.; Frangioni, J. V. Renal Clearance of Quantum Dots. Nat. Biotechnol. 2007, 25 (10), 11651170.

(17) Jaiswal, J. K.; Mattoussi, H.; Mauro, J. M.; Simon, S. M. Long-Term Multiple Color Imaging of Live Cells Using Quantum Dot Bioconjugates. Nat. Biotech. 2003, 21, 47-51.

(18) Christiansen, J.; Goodwin, P. J.; Lanzilotta, W. N.; Seefeldt, L. C.; Dean, D. R. Catalytic and Biophysical Properties of a Nitrogenase Apo-MoFe Protein Produced by a nifBDeletion Mutant of Azotobacter Vinelandii. Biochemistry 1998, 37 (36), 12611-12623.

(19) Milton, R. D.; Abdellaoui, S.; Khadka, N.; Dean, D. R.; Leech, D.; Seefeldt, L. C.; Minteer, S. D. Nitrogenase Bioelectrocatalysis: Heterogeneous Ammonia and Hydrogen Production by MoFe Protein. Energy Environ. Sci. 2016, 9 (8), 2550-2554.

(20) Yu, W. W.; Peng, X. Formation of High-Quality CdS and Other II-VI Semiconductor Nanocrystals in Noncoordinating Solvents: Tunable Reactivity of Monomers. Angew. Chemie - Int. Ed. 2002, 41 (13), 2368-2371.

(21) Courtney, C. M.; Goodman, S. M.; McDaniel, J. A.; Madinger, N. E.; Chatterjee, A.; Nagpal, P. Photoexcited Quantum Dots for Killing Multidrug-Resistant Bacteria. Nat. Mater. 2016, 15 (5), 529-534.

(22) Goodman, S. M.; Singh, V.; Ribot, J. C.; Chatterjee, A.; Nagpal, P. Multiple Energy Exciton Shelves in Quantum-Dot-DNA Nanobioelectronics. J. Phys. Chem. Lett. 2014, 5 (21), 3909-3913.

(23) Goodman, S. M.; Siu, A.; Singh, V.; Nagpal, P. Long-Range Energy Transfer in SelfAssembled Quantum Dot-DNA Cascades. Nanoscale 2015, 7 (44), 18435-18440.

(24) Haram, S. K.; Quinn, B. M.; Bard, a J. Electrochemistry of CdS Nanoparticles: A Correlation between Optical and Electrochemical Band Gaps. J. Am. Chem. Soc. 2001, $123,8860-8861$.

(25) Jasieniak, J.; Califano, M.; Watkins, S. E. Size-Dependent Valence and Conduction Band- 
Edge Energies of Semiconductor Nanocrystals. In ACS Nano; 2011; Vol. 5, pp 58885902.

(26) Amelia, M.; Lincheneau, C.; Silvi, S.; Credi, A. Electrochemical Properties of CdSe and CdTe Quantum Dots. Chem. Soc. Rev. 2012, 41 (17), 5728.

(27) Sundberg, R. J. Interactions of Histidine and Other Imidazole Derivatives with Transition Metal Ions in Chemical and Biological Systems. Chem. Rev. 1974, 74 (4), 471-517.

(28) Hardman, R. A Toxicologic Review of Quantum Dots: Toxicity Depends on Physicochemical and Environmental Factors. Environmental Health Perspectives. 2006, pp $165-172$.

(29) Yong, K.-T. T.; Law, W.-C. C.; Hu, R.; Ye, L.; Liu, L.; Swihart, M. T.; Prasad, P. N. Nanotoxicity Assessment of Quantum Dots: From Cellular to Primate Studies. Chem. Soc. Rev. 2013, 42 (3), 1236-1250.

(30) Hoshino, A.; Fujioka, K.; Oku, T.; Suga, M.; Sasaki, Y. F.; Ohta, T.; Yasuhara, M.;

Suzuki, K.; Yamamoto, K. Physicochemical Properties and Cellular Toxicity of Nanocrystal Quantum Dots Depend on Their Surface Modification. Nano Lett. 2004, 4 (11), 2163-2169.

(31) Lewinski, N.; Colvin, V.; Drezek, R. Cytotoxicity of Nanoparticles. Small 2008, 4 (1), 2649.

(32) Hoffman, B. M.; Lukoyanov, D.; Yang, Z. Y.; Dean, D. R.; Seefeldt, L. C. Mechanism of Nitrogen Fixation by Nitrogenase: The next Stage. Chemical Reviews. 2014, 4041-4062.

(33) Eckert, C.; Xu, W.; Xiong, W.; Lynch, S.; Ungerer, J.; Tao, L.; Gill, R.; Maness, P. C.; $\mathrm{Yu}$, J. Ethylene-Forming Enzyme and Bioethylene Production. Biotechnology for Biofuels. 2014, 7:33.

(34) Lovely, D. R. Electromicrobiology. Annu. Rev. Microbiol. 2012, 66, 391-409 

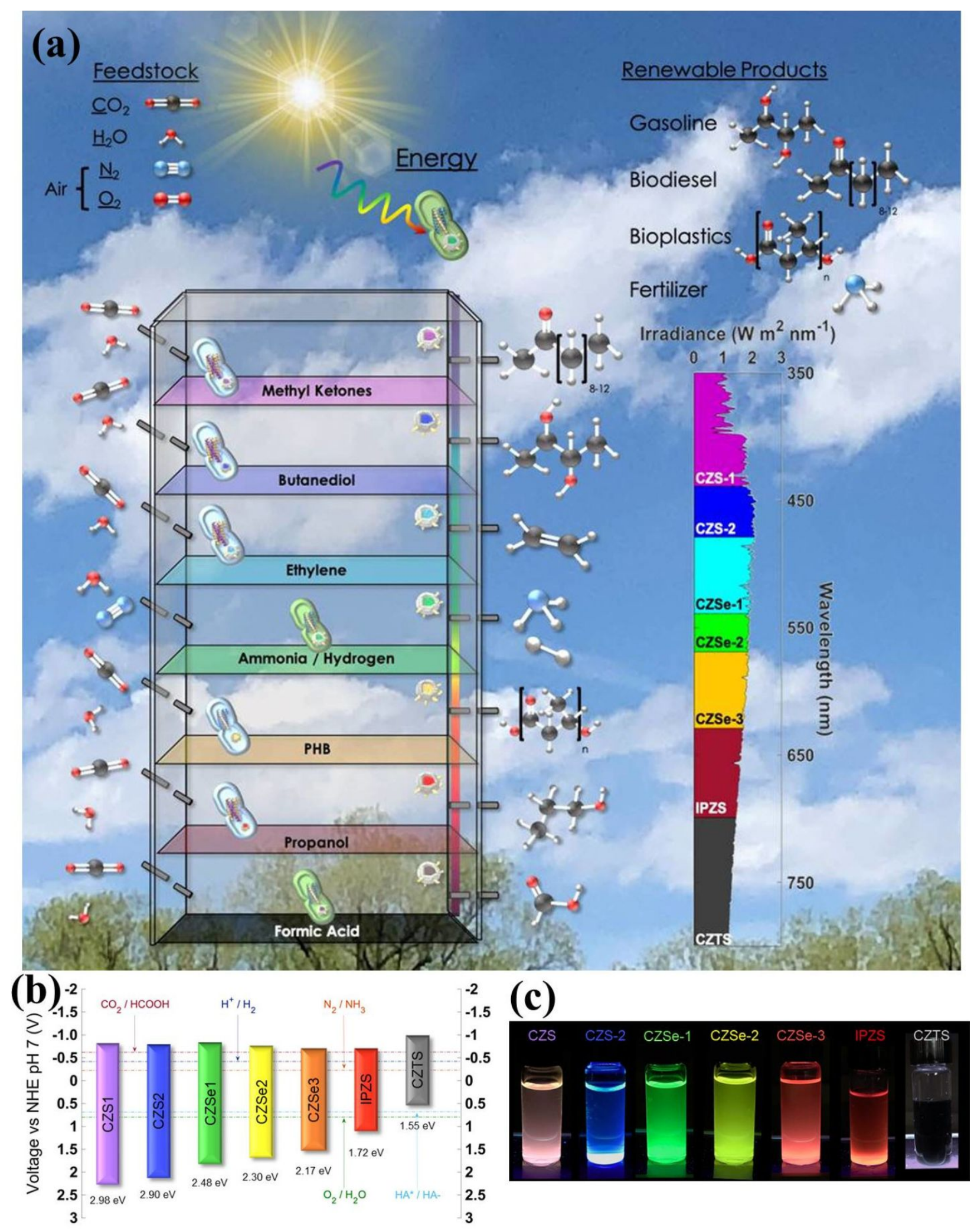

Fig. 1. Designing artificial QD-cell nanorgs with the desired functionality. (a) The design of QD-bacteria nanorgs for light-induced air $-\mathrm{H}_{2} \mathrm{O}-\mathrm{CO}_{2}$ reduction for targeted chemical generation, 
showing the QD uptake, affinity binding and enzyme coupling, and light-triggered redox reaction. Here, QDs absorb sunlight in non-photosynthetic bacteria for direct solar-to-chemical fuel production using air and water as chemical feedstocks. (b) Conduction/valence band (CB/VB) alignment of different semiconductor QDs, with labeled water $\left(\mathrm{H}^{+} / \mathrm{H}_{2}, \mathrm{O}_{2} / \mathrm{H}_{2} \mathrm{O}\right)$, L-ascorbic acid $\left(\mathrm{HA}^{*} / \mathrm{HA}^{-}\right)$, and dinitrogen $\left(\mathrm{N}_{2} / \mathrm{NH}_{4}^{+}\right)$redox potential. (c) Emission image of different semiconductor QDs under 365 nm UV light excitation. (CZS: CdS@ZnS, CZSe: CdSe@ZnS, IPZS: InP@ZnS, CZTS: Cu $Z_{2 n S n S} @ Z$ ZnS, CdS1: 3.6 nm, CdS2: 4.2 nm, CdSe1: 2.3 nm, CdSe2: $2.6 \mathrm{~nm}, \mathrm{CdSe}$ : $4.6 \mathrm{~nm}$, detailed characterization in Supplementary Information, Fig. S1). 


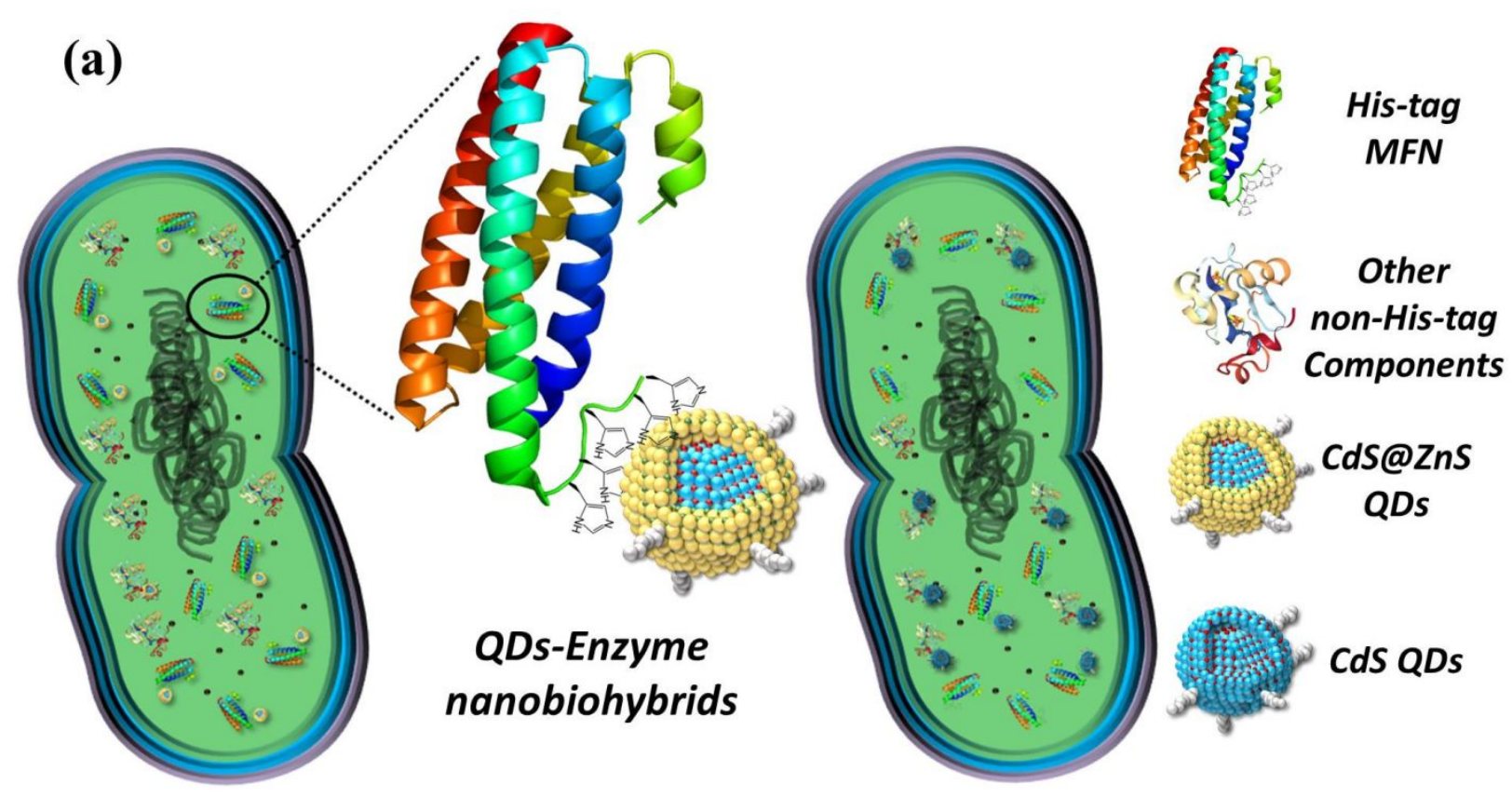

(b)

(d)
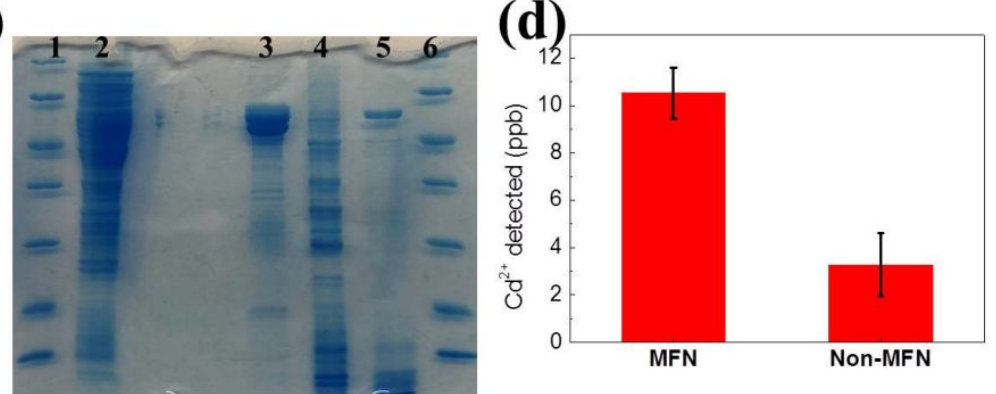

(e)

(c)
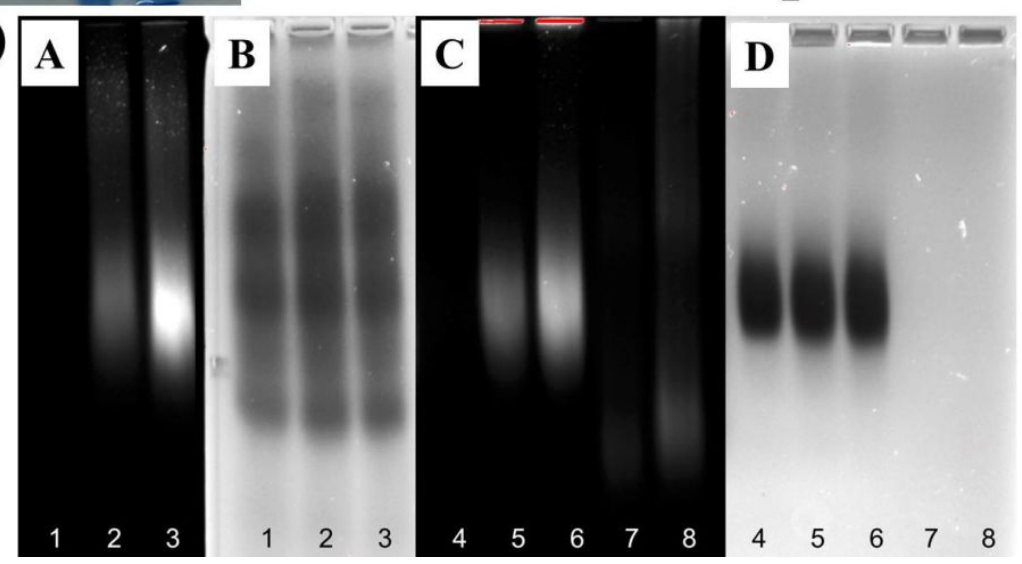

Fig. 2. Affinity binding and self-assembly to His-tagged MFN in cell lysate using ZnS-coated QDs. (a) Schematic illustration of the formation of QDs-A. vinelandii nanorgs. Left: Nanorgs generated with CdS@ZnS core-shell QDs, showing site-selective binding of His-tagged MFN to the zinc-rich facets of the QDs. Right: Nanorgs generated with CdS QDs, showing non-selective QDs to all cellular components binding. (b) SDS-PAGE of protein samples. Lane 1 and 6: protein 
molecular weight marker (From top to bottom: 116.0, 66.2, 45.0, 35.0, 25.0, 18.4, 14.4 kDa). Lane 2: cell lysate from $A$. vinelandii DJ995. Lane 3: purified MoFe nitrogenase (elution from Zn-IMAC column). Lane 4: protein bound to CdS. Lane 5: protein bound to $\mathrm{ZnS}$. (c) Agarose gel electrophoresis of QDs-cell lysate (A, B) and QDs-nitrogenase mixtures (C, D). The migration of QDs and the proteins were indicated by fluorescence $(A, C)$ and Coomassie blue staining (B, D). Lane 1: cell lysate; Lane 2: CZSe1-cell lysate mixture; Lane 3: CZSe2-cell lysate mixture; Lane 4: purified MFN; Lane 5: CZSe1-purified MFN; Lane 6: CZSe2-purified MFN; Lane 7: CZSe1; Lane 8: CZSe2. (d) Cadmium detected from the MFN and non-MFN band of the CZSe2-cell lysate AGE lane (Fig.2c, lane 3). The residual cadmium detected in the non-MFN band was limited mainly by the detection limit of the instrument. (e) Biocatalytic product generation (hydrogen production, converted to total electron generation) with QDs-CL enzyme biohybrids. Core refers to QDs (CdS and CdSe) without ZnS shell, and core/shell refers to the QDs with nominal 2ML $\mathrm{ZnS}$ shell. 
(a)

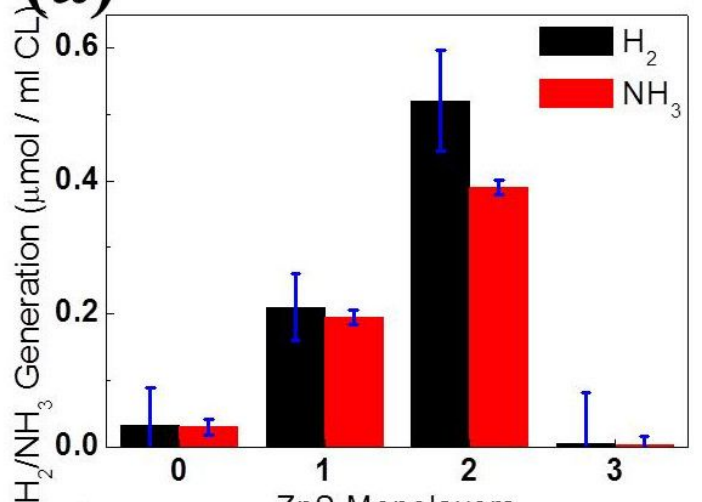

(c)

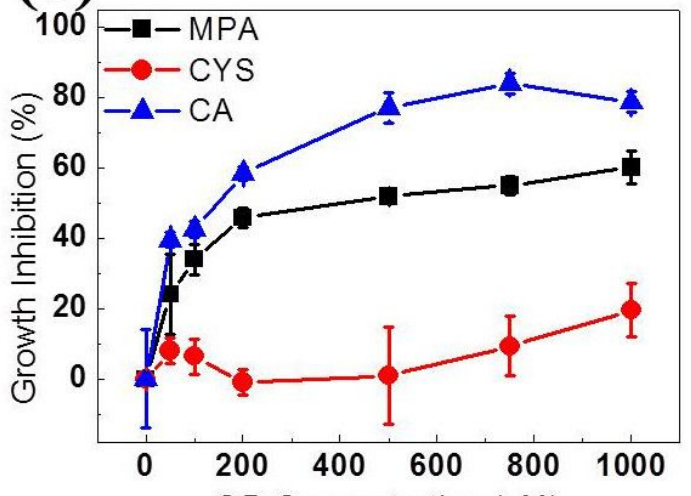

(e)

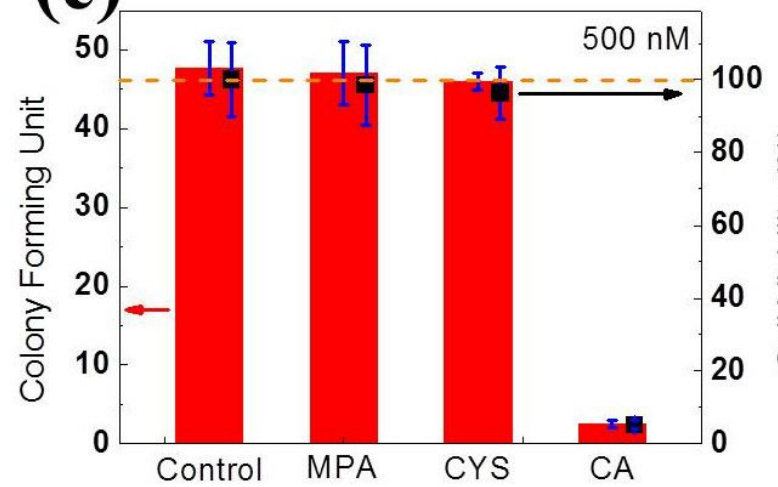

(b)

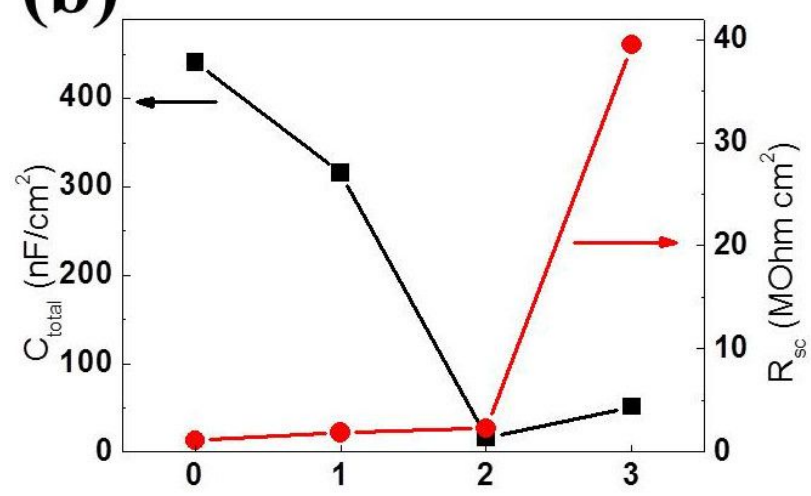

(d)

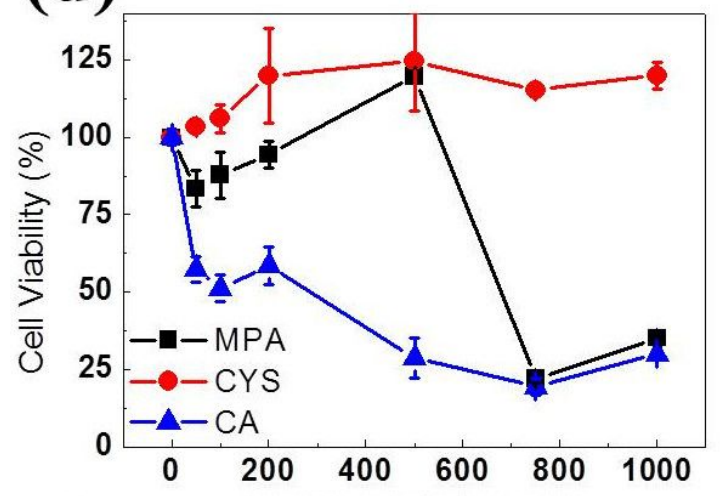

(f)

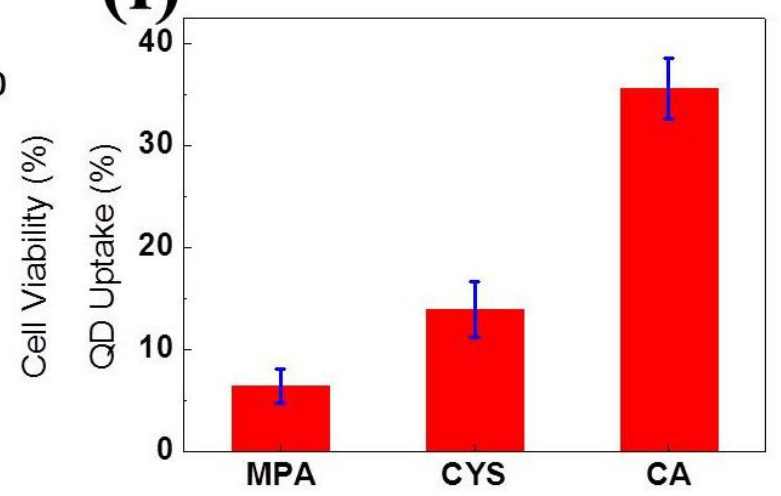

Fig. 3. Designing QDs for chemical coupling, energetic coupling between optoelectronic states and cellular process, appropriate interfaces, uptake and self-assembly, and ensuring biocompatibility. (a) Net production of the cell lysate-QD hybrids, showing the light-activated $\mathrm{H}_{2}$ and $\mathrm{NH}_{3}$ generation using CZS QDs with variation of $\mathrm{ZnS}$ monolayers (0 3). (b) Evolution of $\mathrm{C}_{\text {total }}\left(\mathrm{C}_{\mathrm{sc}}+\mathrm{C}_{\mathrm{t}}\right)$ and $\mathrm{R}_{\mathrm{sc}}$ with the increase of $\mathrm{ZnS}$ shell thickness, obtained from the equivalent circuit (Fig.S2h) fit from the electrochemical impedance spectroscopy (EIS) data (Fig.S2g). (c) Inhibition of cell growth (using cell growth curve in nitrogen-free Burk media, under dark 
condition) with different ligand-capped QDs, calculated from Fig.S8a-c. (d) Cell viability (using resazurin assay) with cells treated with different ligand-capped QDs (after performing the photocatalytic tests), calculated from Fig.S9d-f. (e) Colony forming unit of cells treated with different ligand-capped QDs. "Control" refers to no quantum dots control treatment. (f) Cellular uptake of different ligand-capped QDs. 


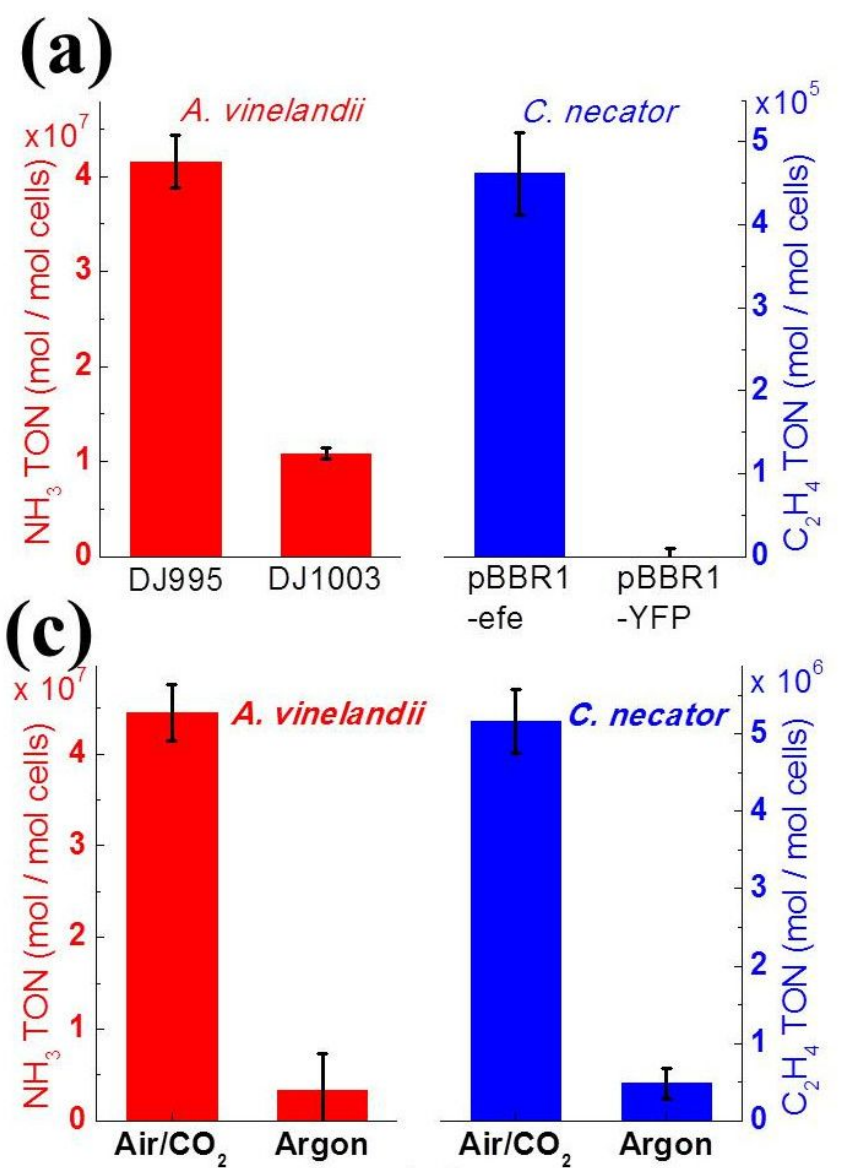

(b)
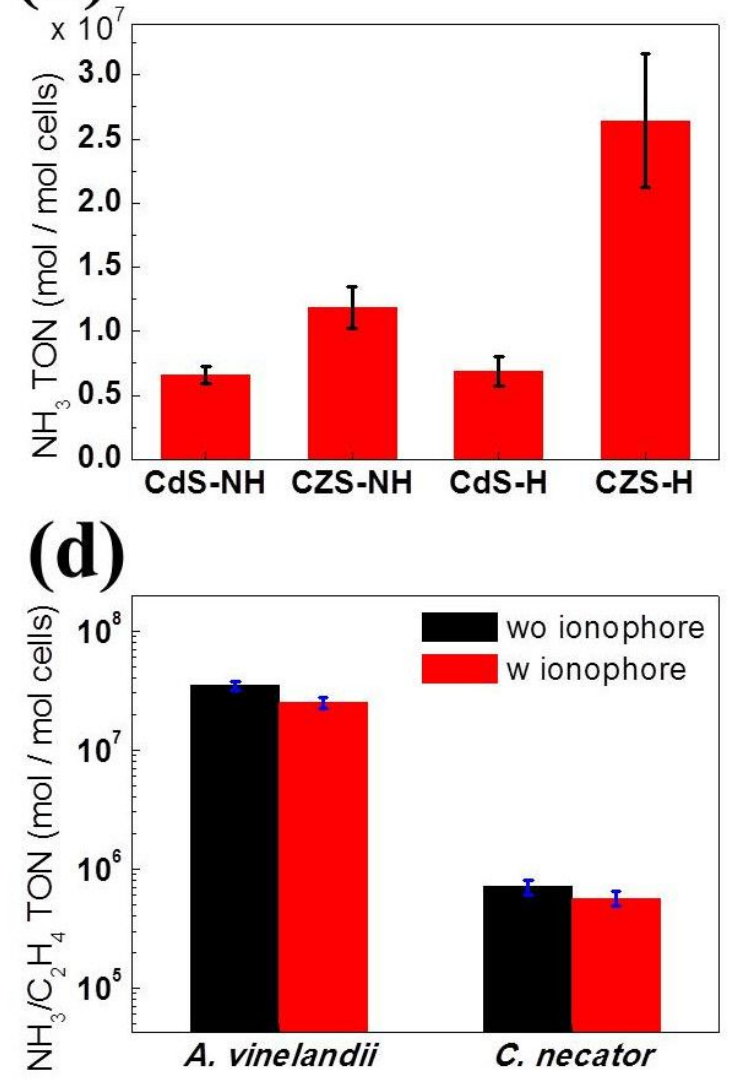

(e)

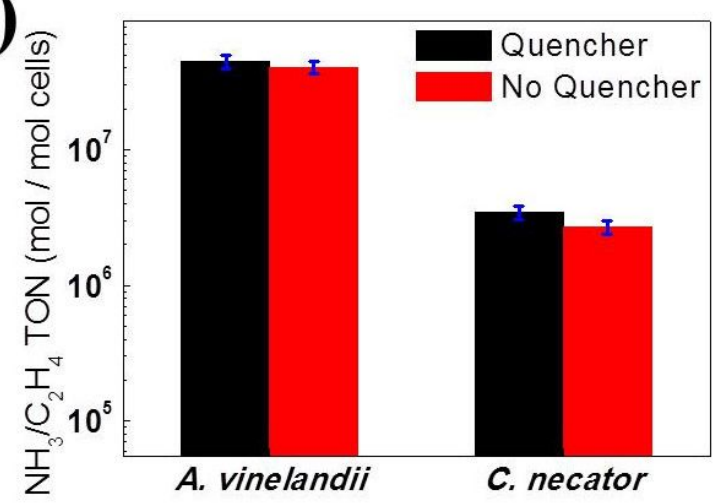

Fig. 4. Evidence of light-driven chemical generation from nanorgs. (a) Different bacteria strains for $\mathrm{NH}_{3}$ (A. vinelandii DJ995 and DJ1003) and $\mathrm{C}_{2} \mathrm{H}_{4}$ (C. necator pBBR1-efe and pBBR1YFP) production. (b) Ammonia production from nanorgs made from $A$. vinelandii with His-tagged MFN (DJ995, indicated as "H”) or non-His-tagged MFN (wild-type, indicated as "NH”) and CdS (without ZnS shell) or CZS (with two-monolayer ZnS shell) QDs. (c) Production of $\mathrm{C}_{2} \mathrm{H}_{4}$ and $\mathrm{NH}_{3}$ in $\mathrm{CO}_{2}$ /air or argon. (d) $\mathrm{NH}_{3}$ and $\mathrm{C}_{2} \mathrm{H}_{4}$ production with $(0.5 \mathrm{mM})$ and without the addition of 
ionophore (0.5 mM 2,4-DNP). (e) $\mathrm{NH}_{3}$ and $\mathrm{C}_{2} \mathrm{H}_{4}$ production with and without the addition of sacrificial donor/quencher (5 mM L-ascorbic acid). 
(a)

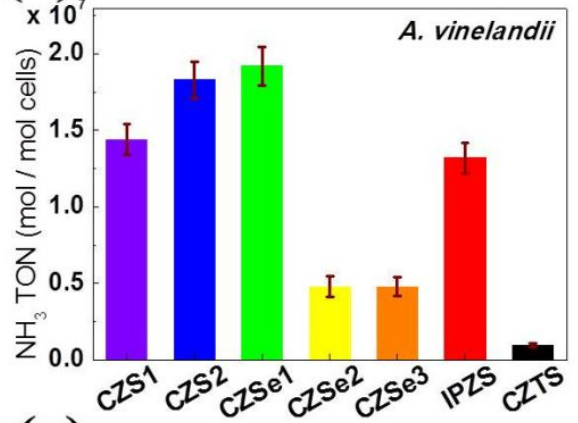

(c)

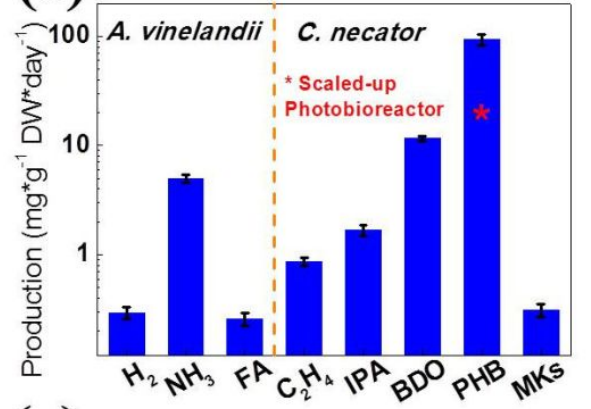

$(\mathbf{e})$

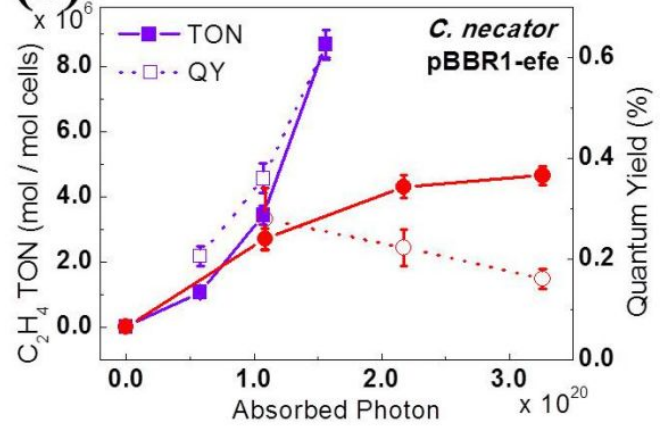

(g)

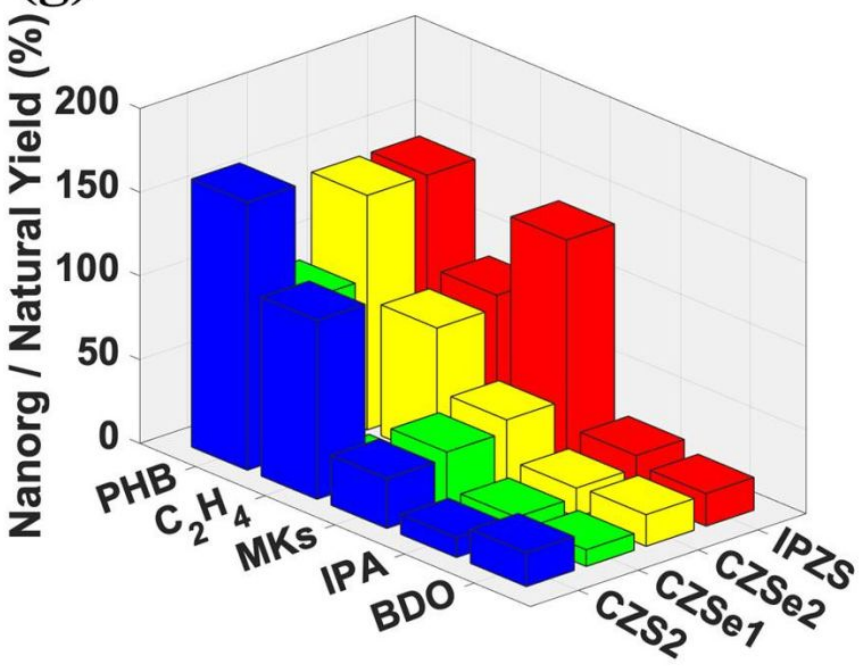

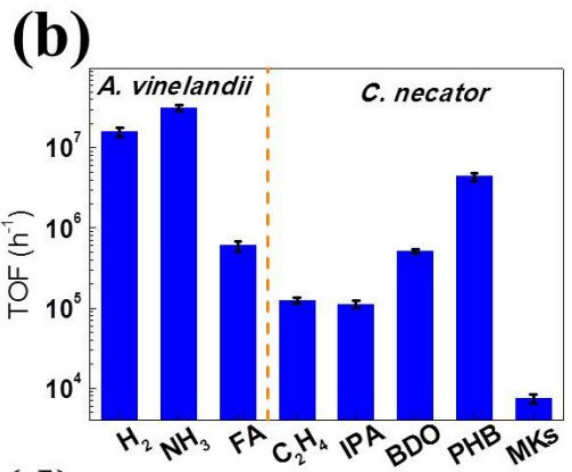

$(\mathbf{d})$

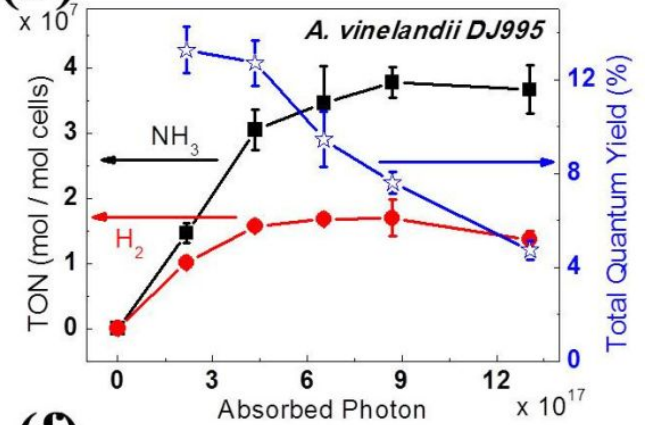

(f)

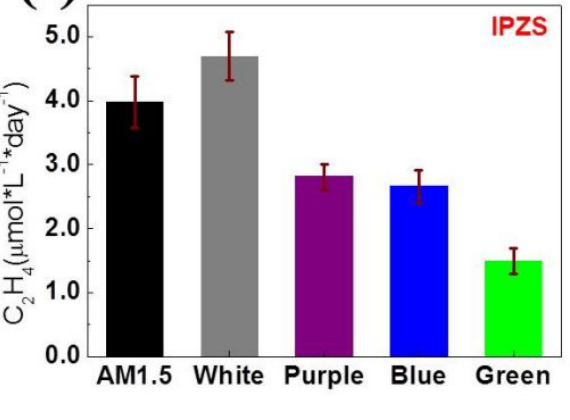


Fig.5. Nanorg microbial factories for fuel and chemical production with variations of different QDs, bacterial strains, and light photon energies and flux. (a) $\mathrm{NH}_{3}$ turnover number (TON) with nanorgs made from different QDs. (b) Turnover frequency (TOF) of different fuels with nanorgs made from CZS QDs and different bacteria strains. (c) Cumulative specific productivity of different fuels and biochemical (represented as per gram cell dry weight per day) with nanorgs made from CZS QDs and different bacteria strains. (d, e) Time trace (represented as against absorbed photon numbers) of $\mathrm{NH}_{3}, \mathrm{H}_{2}$ (with CZS QDs and A. vinelandii DJ955), and $\mathrm{C}_{2} \mathrm{H}_{4}$ (with CZS or IPZS QDs and C. necator pBBR1-efe) production, showing the turnover number and quantum yield with time. (f) $\mathrm{C}_{2} \mathrm{H}_{4}$ production (with IPZS QDs and C. necator pBBR1-efe) under different light sources irradiation. (g) Comparison of chemical production yield for $\mathrm{PHB}, \mathrm{C}_{2} \mathrm{H}_{4}$, MKS, IPA, and BDO using light-activated nanorgs and natural growth (organolithotrophic with sugars) conditions. Strains were generated as detailed in Supplementary methods section 6.1.16.1.4. The 3D plot represents nanorgs-to-natural production ratio. 


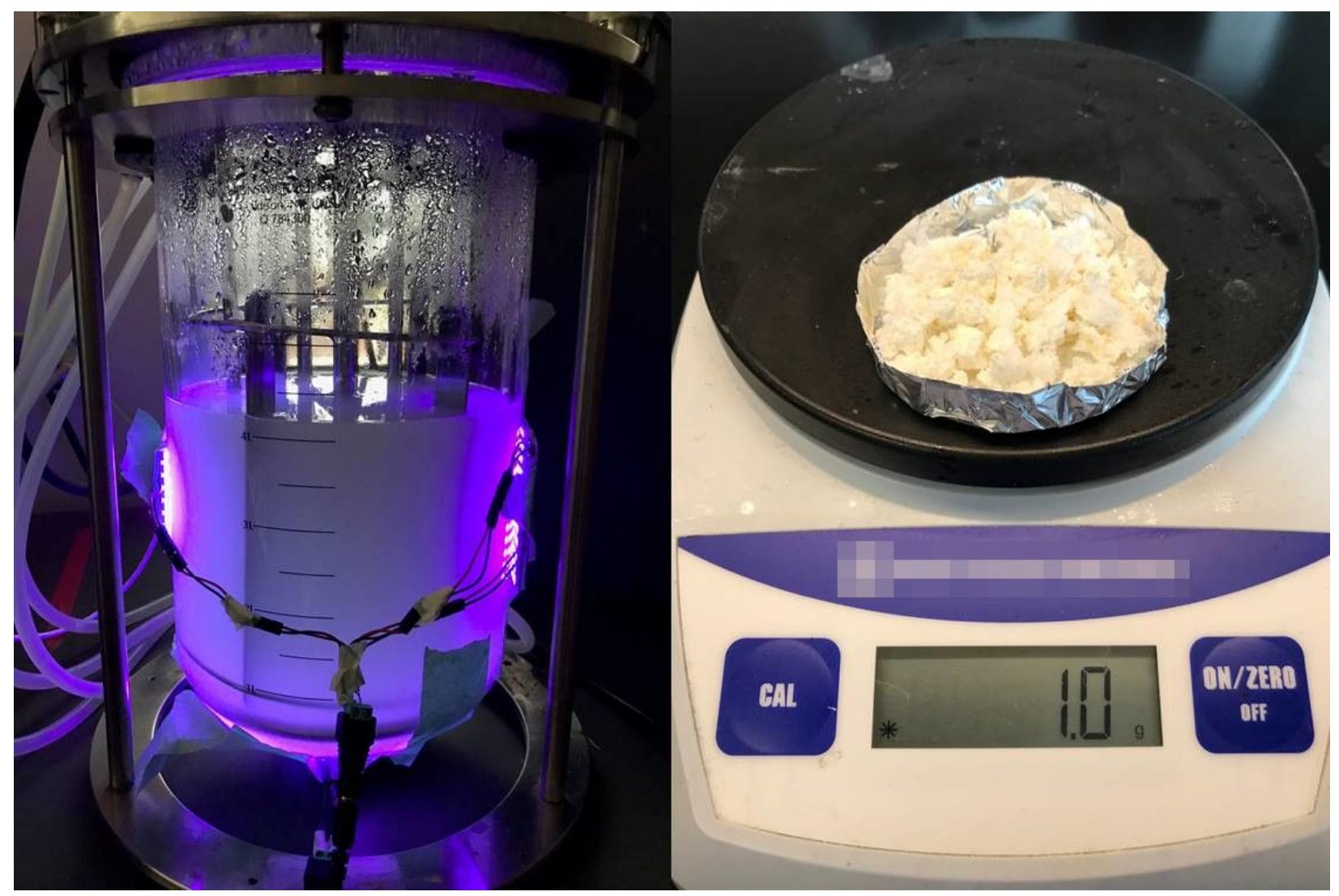

Fig.6. Scaled-up production using nanorgs in a bioreactor. (Left) A photobioreactor with 4 liters of nanorgs-buffered water suspension, with wild-type C. necator pBBR1-YFP, CZS2 QDs, $400 \mathrm{~nm}$ light irradiation, for PHB production. (Right) The PHB extracted from the nanorgs, showing a total dry weight of 1.0 gram. 


\section{TOC GRAPHIC}

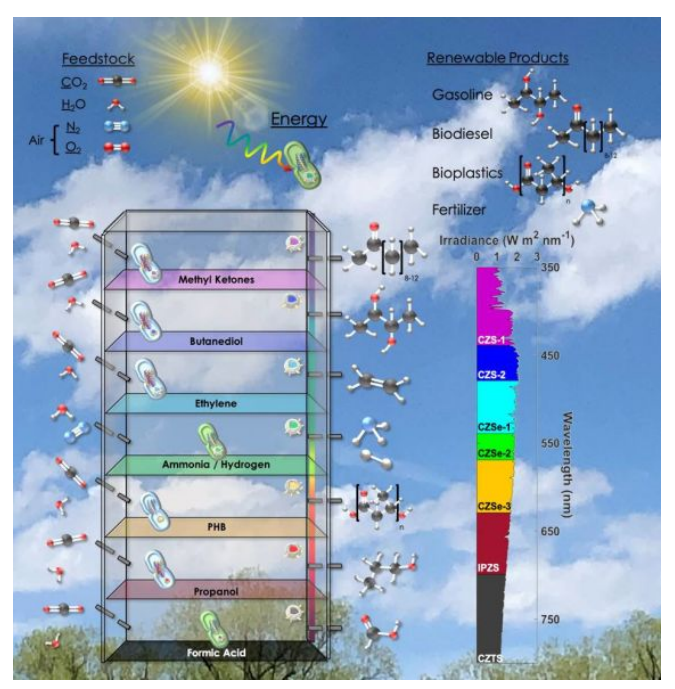




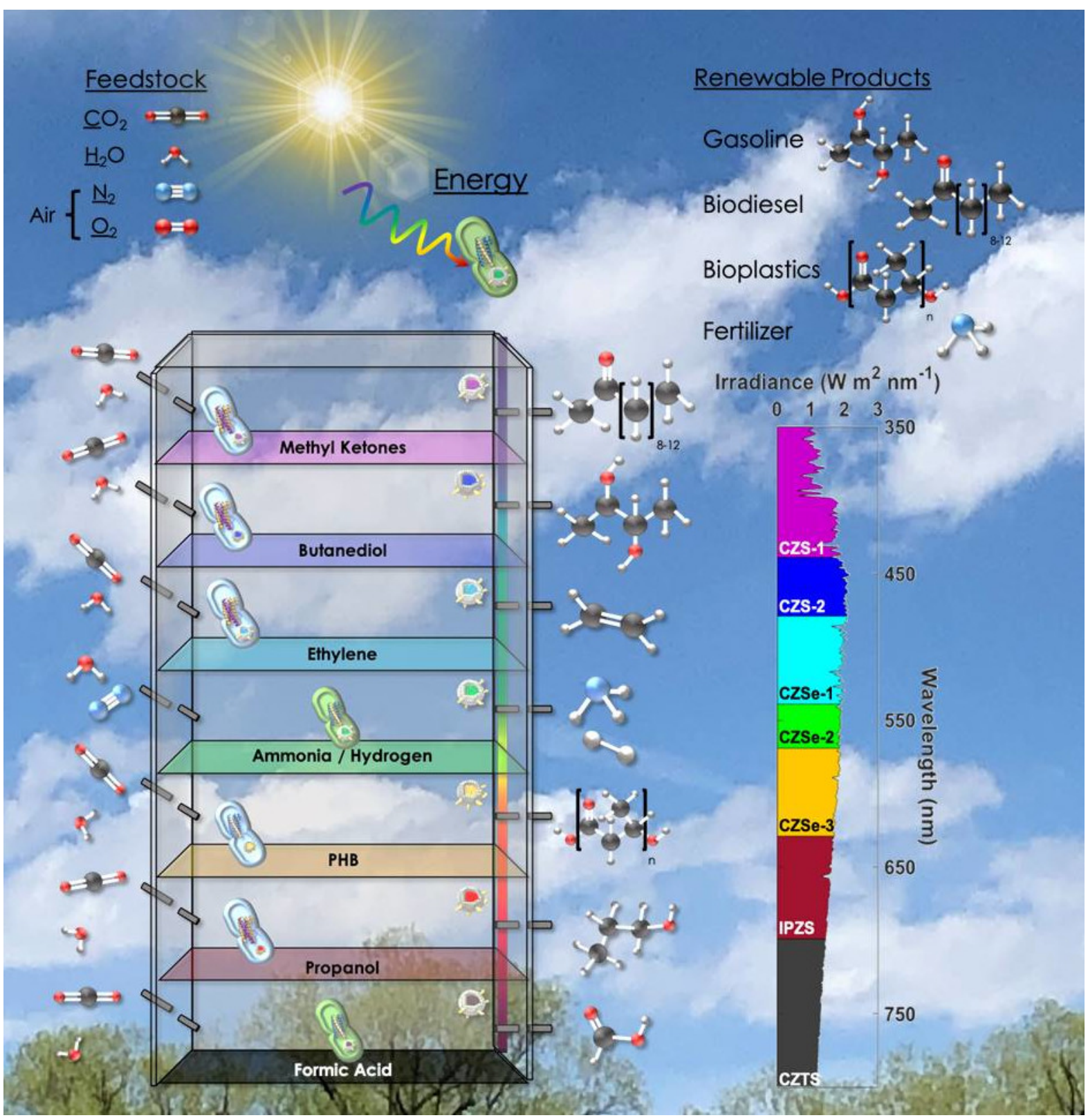

